\title{
Manganese Catalyzed Regioselective C-H Alkylation: Experiment and Computation
}

\author{
Chengming Wang, ${ }^{[\mathrm{a}], \dagger}$ Bholanath Maity, ${ }^{[\mathrm{b}], \dagger}$ Luigi Cavallo* ${ }^{[\mathrm{b}]}$ and Magnus Rueping**a,b] \\ [a] Institute of Organic Chemistry, RWTH Aachen University, Landoltweg 1, 52074 Aachen, Germany \\ ${ }^{[b]}$ KAUST Catalysis Center, King Abdullah University of Science and Technology (KAUST), Thuwal 23955-6900, Saudi \\ Arabia
}

ABSTRACT: A new efficient manganese-catalyzed selective C2-alkylation of indoles via carbenoid insertion has been achieved.
The newly developed $\mathrm{CH}$ functionalization protocol provides access to diverse products and shows good functional group toler-
ance. Mechanistic and computational studies support the formation of a $\mathrm{Mn}(\mathrm{CO})_{3}$ acetate complex as the catalytically active species.

Indole motifs are core structures present in numerous natural products, pharmaceuticals, and other functional molecules. ${ }^{1}$ Thus, a considerable number of synthetic methods have been developed for their synthesis. Nevertheless, the search for more straightforward and economical ways to accomplish both the synthesis and direct modification of indoles is desirable. ${ }^{2}$ Among the methods known to date, the transition-metal catalyzed direct $\mathrm{C}-\mathrm{H}$ functionalization of indoles is important as it overcomes the need for prefunctionalized reaction partners. In addition it often tolerates a wide substrate scope with controlled regioselectivity and, therefore, becomes a powerful and useful synthetic tool. While elegant methods for the introduction of aryl and alkenyl groups have been reported, protocols for direct and regioselective alkylation are still limited. ${ }^{3}$ Furthermore, most of the $\mathrm{C}-\mathrm{H}$ functionalization protocols still relay on the use of precious second- and third-row transition metals (eg. Rh, Ir, Pd, and $\mathrm{Ru}$ ). More recently, several groups including ours reported on the use of manganese complexes in the $\mathrm{C}-\mathrm{H}$ activation of heteroarenes. ${ }^{4}$ Manganese is a first-row early transition metal, yet naturally abundant and inexpensive. Recently, various reports on its use in the activation of inert C$\mathrm{H}$ bonds have appeared. ${ }^{4-6}$

Hence, we wondered whether manganese salts could be applied in the regioselective alkylation of indoles via carbenoid insertion (Scheme 1). ${ }^{7,8}$ This would not only be the first example of such a manganese catalyzed transformation but would allow a simple, direct and straightforward functionalization using readily accessible reactants and catalyst.

Scheme 1. Mn-catalyzed selective C-H alkylation of indoles.

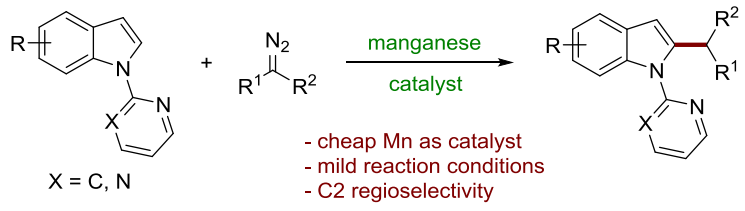

Initially, our study was carried out by examining the reaction between $N$-pyrimidinyl indole (1a) and dimethyl 2diazomalonate $(\mathbf{2 a})$ in the presence of $\left[\mathrm{MnBr}(\mathrm{CO})_{5}\right]$ in $\mathrm{THF}$ under argon (Table 1, entry 1). However, no product was detected. To our delight, with the use of $\mathrm{NaOAc}$ as an additive, the desired product 3a was isolated in 52\% yield (Table 1, entry 2). This may be explained by the formation of a manganese acetate complex in which the acetate facilitates the $\mathrm{CH}$ activation. Next, we evaluated the influence of further additives (Table 1, entries 3-6). When triphenyl phosphine $\mathrm{Ph}_{3} \mathrm{P}$ was used, the yield drastically dropped to $15 \%$, while in the presence of $\mathrm{Et}_{3} \mathrm{~N}$ no reaction was observed.

Table 1. Optimization of the reaction conditions. ${ }^{a}$

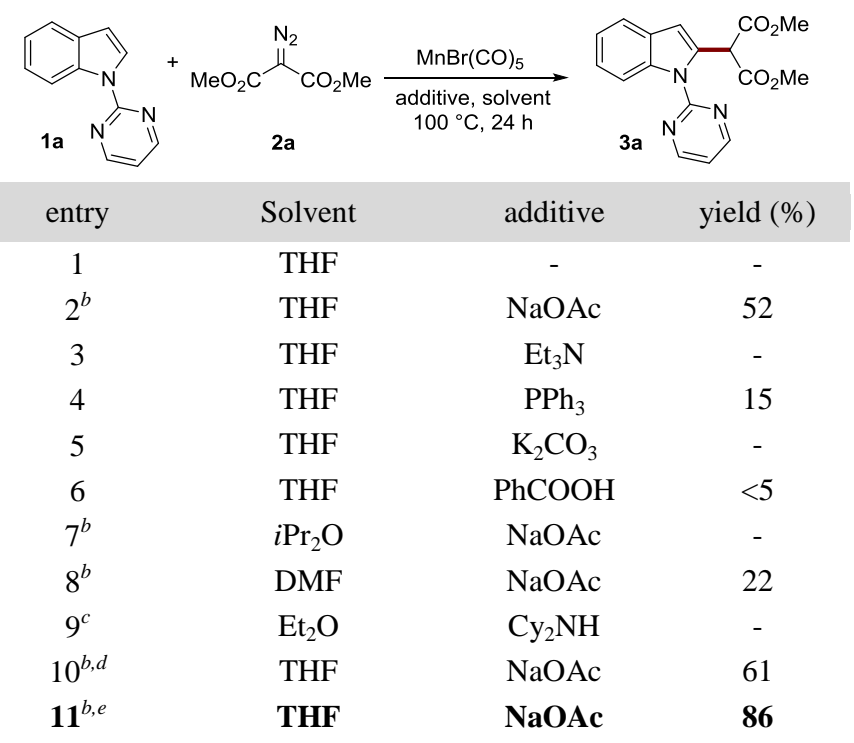

${ }^{a}$ Reaction conditions: 1a ( $0.2 \mathrm{mmol}, 1.0$ equiv), 2a (1.5 equiv), $\mathrm{MnBr}(\mathrm{CO})_{5}(10 \mathrm{~mol} \%)$, additive (0.5 equiv), solvent, $100{ }^{\circ} \mathrm{C}, 24$ $\mathrm{h}$, yield for isolated product. ${ }^{b} 2.0$ equiv additive. ${ }^{c} 0.2$ equiv additive. ${ }^{d} 50{ }^{\circ} \mathrm{C}, 48$ h. ${ }^{e} \mathbf{1 a}$ (1.2 equiv), $2 \mathbf{a}$ (1.0 equiv), $50{ }^{\circ} \mathrm{C}, 60 \mathrm{~h}$.

Other additives also failed to improve the yield (for details see Supporting Information). We also tested different solvents, however low or no yield was obtained (Table 1, entries 7-9). It is worth noting that by lowering the temperature to $50{ }^{\circ} \mathrm{C}$, a slightly higher yield was obtained (Table 1 , entry 10 vs 2 ). Finally, upon inverting the ratio of the reagents and use of two 
equiv of $\mathrm{NaOAc}$ in $\mathrm{THF}$ at $50{ }^{\circ} \mathrm{C}$ the product 3a was obtained in $86 \%$ yield (Table 1 , entry 11 ).

Scheme 2. Substrates scope of the managnese catalyzed CH-alkylation ${ }^{a}$

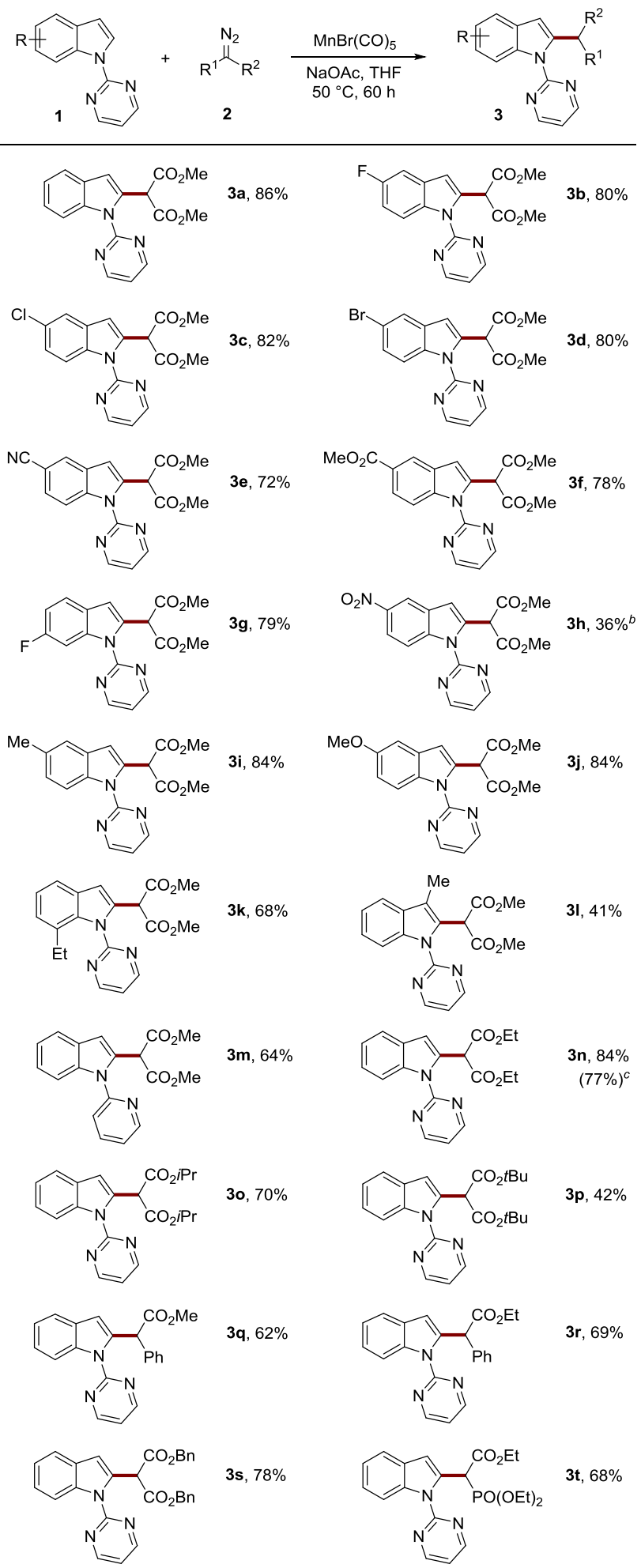

${ }^{a}$ Reaction conditions: 1a ( $0.36 \mathrm{mmol}, 1.2$ equiv), $\mathbf{2 a}(0.3 \mathrm{mmol}$, 1.0 equiv), $\mathrm{MnBr}(\mathrm{CO})_{5}(10 \mathrm{~mol} \%), \mathrm{NaOAc}(0.6 \mathrm{mmol}, 2.0$ equiv), THF, $50{ }^{\circ} \mathrm{C}, 60 \mathrm{~h}$, yields for isolated compounds. ${ }^{b}$ Reaction on a $1 \mathrm{mmol} \mathrm{scale,} 62 \mathrm{~h} .{ }^{c} \mathrm{DMF} / \mathrm{THF}(2: 1)$ as solvent.
With the optimized conditions in hand we evaluated the generality of this protocol. As illustrated in Scheme 2, the newly developed protocol has a good functional group tolerance as both electron deficient and electron rich indoles can be applied in this reaction (1a-g, 1i-k). 3-Me substituted indole $\mathbf{1 l}$ also reacts in this transformation despite the steric hindrance. It is worth noting that $N$-pyridinyl indole 1m underwent alkylation smoothly. Various diazo compounds are equally effective and the corresponding products $\mathbf{3 n - t}$ were obtained in good to high yields. In addition, an experiment performed on a $1 \mathrm{mmol}$ scale provided the corresponding product $\mathbf{3 n}$ in $77 \%$ yield.

In order to gain insight into the mechanism of this reaction, we conducted control and deuteration experiments which indicate that the reversible $\mathrm{C}-\mathrm{H}$ cleavage of $\mathbf{1 a}$ is the rate determining step. ${ }^{9}$ Supported by these experimental results we performed DFT calculations to define a possible reaction pathway. Preliminary calculations indicated that transformation of $\mathrm{MnBr}(\mathrm{CO})_{5}$ to $(\mathrm{CO})_{4} \mathrm{Mn}\left(\kappa^{2}-\mathrm{OAc}\right)$ via $(\mathrm{CO})_{5} \mathrm{Mn}\left(\kappa^{1}-\mathrm{OAc}\right)$, in presence of $\mathrm{NaOAc}$, is an almost thermoneutral process (see Scheme 3).

Scheme 3. Energetics of catalyst activation, in kcal/mol.

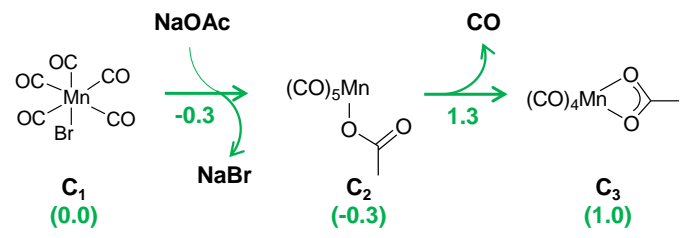

We thus started investigating the reactivity using $(\mathrm{CO})_{4} \mathrm{Mn}\left(\kappa^{2}-\right.$ $\mathrm{OAc}), \mathbf{C}_{\mathbf{3}}$ in Figure 1, as starting point. Coordination of the substrate $\mathbf{1 a}$ to $\mathbf{C}_{\mathbf{3}}$ leads to intermediate $\mathbf{1 - I}$, a step endergonic by $16.0 \mathrm{kcal} / \mathrm{mol}$. Coordination of $\mathbf{1 a}$ also requires that the $\kappa^{2}-$ coordinated OAc ligand switches to a $\kappa^{1}$-binding mode. $\mathrm{C}-\mathrm{H}$ activation from 1-I leads to the observed intermediate Mn-I via the high energy transition state $[\mathbf{1 - 2}-\mathbf{I}]^{*}\left(\Delta G^{\ddagger}=33.5\right.$ $\mathrm{kcal} / \mathrm{mol}),{ }^{10}$ and synchronous elimination of $\mathrm{AcOH}$ from the filled coordination sphere of $\mathrm{Mn}$. To proceed further along the reaction pathway a $\mathrm{CO}$ molecule has to dissociate from $\mathrm{Mn}-\mathbf{I}$ to create a vacant site for coordination of the diazo-compound 2a. This step leads to 3 and it is endergonic by $16.8 \mathrm{kcal} / \mathrm{mol}$.

An alternative entry to the catalytic cycle is via dissociation of a $\mathrm{CO}$ molecule from the starting species $\mathbf{C}_{3}$, leading to the three carbonyl $(\mathrm{CO})_{3} \mathrm{Mn}\left(\kappa^{2}-\mathrm{OAc}\right)$ species $\mathbf{C}_{4}$, with a free energy penalty of $12.6 \mathrm{kcal} / \mathrm{mol}$. Exergonic $(-4.1 \mathrm{kcal} / \mathrm{mol})$ coordination of the substrate to $\mathbf{C}_{4}$ leads to intermediate $\mathbf{1}$. The next step corresponds to activation of the ortho $\mathrm{C}-\mathrm{H}$ bond of the coordinated indole by the OAc ligand. This step occurs via the six membered transition state [1-2] (Figure 1) and has a relatively low activation energy $\left(\Delta G^{\ddagger}=12.3 \mathrm{kcal} / \mathrm{mol}\right)$. The resulting intermediate $\mathbf{2}$, has the formed carboxylic acid coordinated to the metal. Further progress of the reaction requires endergonic (by $6.0 \mathrm{kcal} / \mathrm{mol}$ ) dissociation of $\mathrm{AcOH}$ to generate intermediate $\mathbf{3}$, with a vacant coordination site to accommodate the diazo-compound $\mathbf{2 a}$.

Comparison of the two alternative pathways leading to $\mathbf{3}$ and Mn-I (red and blue pathways in Figure 1), suggests that initial dissociation of $\mathrm{CO}$ from $\mathbf{C}_{\mathbf{3}}$ leading to $\mathbf{C}_{\mathbf{4}}$ (blue pathway in Figure 1) is favored, considering the clearly higher energy of transition state $[\mathbf{1 - 2}-\mathbf{I}]^{*}$ compared to transition state [1-2]. Eventually, coordination of a $\mathrm{CO}$ molecule to $\mathbf{3}$ leads to the experimentally observed species Mn-I. 


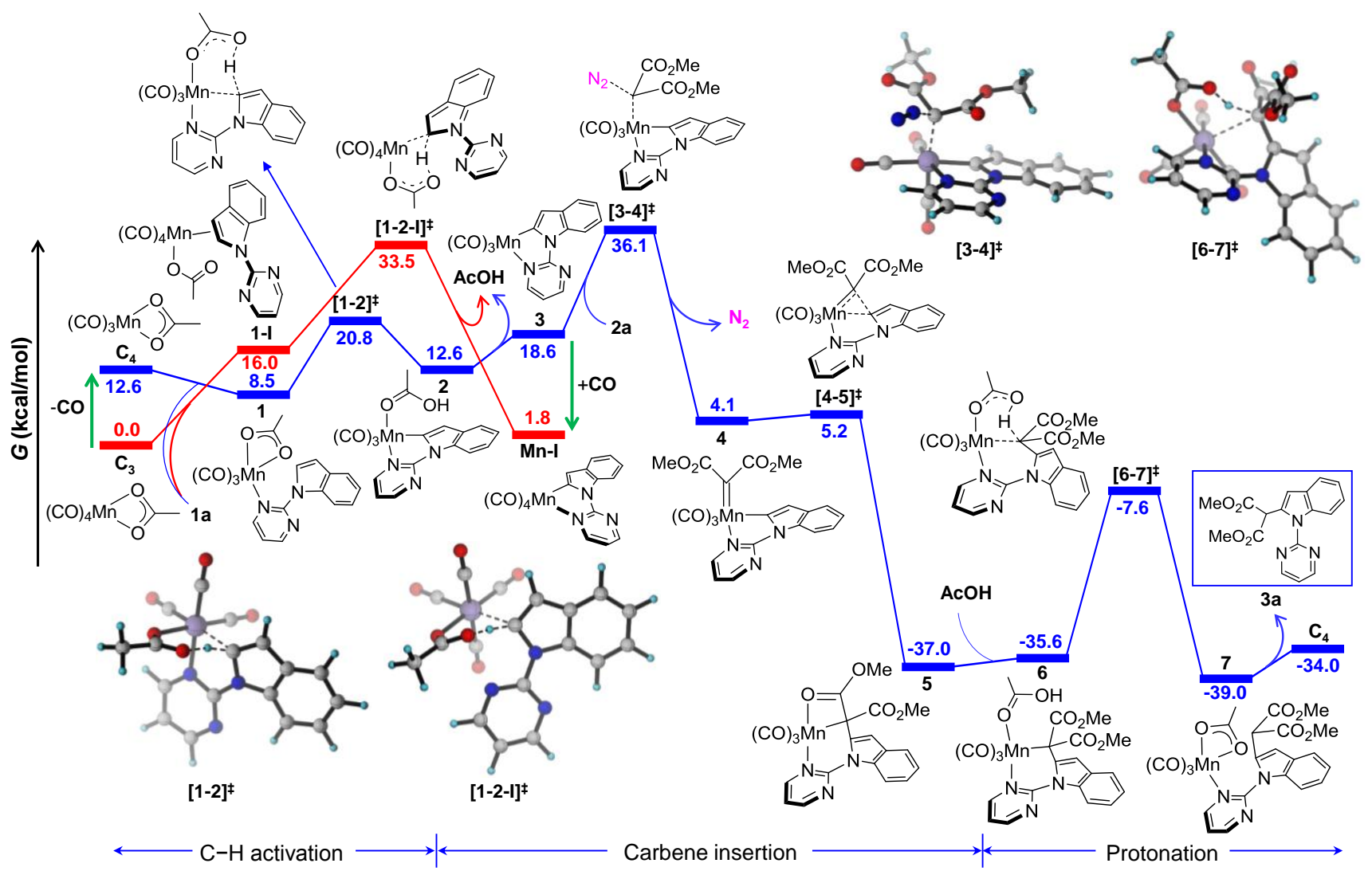

Figure 1. Computed free energy surface for the $\mathbf{C}-\mathbf{H}$ alkylation of $\mathrm{N}$-pyrimidinyl indole (1a) with dimethyl 2-diazomalonate (2a). Free energies in solution (THF as the solvent) at the M06(PCM)/TZVP//PBE0/SVP(H,C,O,N)/TZVP(Mn,Br) level are displayed.

However, under reaction conditions $\mathrm{CO}$ in the solution will equilibrate with $\mathrm{CO}$ in the gas above, shifting the equilibrium towards the formation of $\mathrm{CO}$ dissociated species, such as $\mathbf{C}_{\mathbf{4}}$ and Mn-I.

Once the first section of the catalytic cycle, $\mathrm{C}-\mathrm{H}$ activation of the substrate, has been clarified, we proceeded to the second section, which is the carbene insertion into the $\mathrm{Mn}-\mathrm{C}$ bond starting from $\mathbf{3}$. Coordination of $\mathbf{2 a}$ to $\mathbf{3}$, via transition state [3$4]^{*}$, generates the stable metal-carbene complex 4. Transition state [3-4] involves formation of the Mn-carbene bond with concomitant liberation of $\mathrm{N}_{2}$ (Figure 1 ). The calculated activation energy is moderately high $\left(\Delta G^{\ddagger}=27.6 \mathrm{kcal} / \mathrm{mol}\right)$ due to the rupture of the quite strong $\mathrm{C}-\mathrm{N}$ double bond of $\mathbf{2 a}$. Intramolecular carbene insertion into the $\mathrm{Mn}-\mathrm{C}$ bond of 4 via transition state $[\mathbf{4 - 5}]^{\ddagger}$ is not relevant from a kinetic point of view, due to a very low activation energy, $\Delta G^{\star}=1.1 \mathrm{kcal} / \mathrm{mol}$ only. The stability gained with transformation of $\mathbf{4}$ to $\mathbf{5}$ amounts to $41.1 \mathrm{kcal} / \mathrm{mol}$. Coordination of one ester group of the inserted carbene saturates the coordination sphere of $\mathrm{Mn}$ in 5 (Figure 1). Formation of intermediate $\mathbf{5}$ completes the carbene-insertion section of the reaction pathway. The last section of the reaction pathway, protonation and release of the alkylated product, starts with thermoneutral displacement of the coordinated ester group in $\mathbf{5}$ by a $\mathrm{AcOH}$ molecule, and leads to complex 6. Proton transfer from the coordinated $\mathrm{AcOH}$ to the $\mathrm{C}$-atom of the $\mathrm{Mn}-\mathrm{C}$ (indole) bond leads to intermediate 7 via transition state $[6-7]^{*}$ and a rather high activation energy $\left(\Delta G^{*}=29.4 \mathrm{kcal} / \mathrm{mol}\right)$. Transition state $[6-7]^{*}$ is characterized by synchronous $\mathrm{C}-\mathrm{H}$ bond formation and $\mathrm{Mn}-\mathrm{C}$ bond elongation (Figure 1). Dissociation of the formed 2alkyl-indole (3a) from 7 regenerates the active species $\mathbf{C}_{\mathbf{4}}$, which is ready to start another catalytic cycle. The observation that a $\mathrm{Mn}(\mathrm{CO})_{3} \mathrm{OAc}$ is the catalytically active species is in contrast to previous reports in which $\mathrm{Mn}(\mathrm{CO})_{4}$ complexes are proposed.

The energy profile displayed in Figure 1 reveals that the initial $\mathrm{C}-\mathrm{H}$ activation step via transition state $[\mathbf{1 - 2}]^{*}$ is feasible $\left(\Delta G^{\ddagger}\right.$ $=12.3 \mathrm{kcal} / \mathrm{mol}$ ) and followed by activation of the diazo compound via transition state $[3-4]^{\ddagger}\left(\Delta G^{\ddagger}=27.6 \mathrm{kcal} / \mathrm{mol}\right)$. The highest barrier $\left(\Delta G^{*}=29.4 \mathrm{kcal} / \mathrm{mol}\right)$ corresponds to the protonation step generating the alkylated-indole via transition state [6-7]. The calculated isotopic effect $\mathrm{K}_{\mathrm{H} / \mathrm{D}}$ values for the more demanding $\mathrm{C}-\mathrm{H}$ bond formation step $(\mathbf{5} \rightarrow \mathbf{7})$ is 2.9 , in good agreement with the experimental value of 1.9 , further validating the proposed reaction pathway.

In conclusion, we report our preliminary results regarding the development of a new, cheap and efficient Mn-catalyzed selective C2-alkylation of indoles. This protocol is characterized by its high functional group tolerance, providing a practical and versatile way to synthesize a wide range of alkylated indoles starting from readily available starting materials. Computational studies support the notion that the alkylation proceeds via a manganese carbenoid intermediate and that a $\mathrm{Mn}(\mathrm{CO})_{3}$ complex formed during the first cycle is the catalytically active species. Further exploration and application of this 
manganese catalysis is currently in progress and will be reported in due course.

\section{ASSOCIATED CONTENT}

Supporting Information. Detailed experimental procedures, spectral data for all compounds, and copies of ${ }^{1} \mathrm{H},{ }^{13} \mathrm{C},{ }^{19} \mathrm{~F}$, and

${ }^{119} \mathrm{Sn}$ NMR spectra. This material is available free of charge via the Internet at http://pubs.acs.org.

\section{AUTHOR INFORMATION}

\section{Corresponding Author}

* magnus.rueping@ rwth-aachen.de

* luigi.cavallo@kaust.edu.sa

\section{Author Contributions}

The manuscript was written through contributions of all authors. All authors have given approval to the final version of the manuscript.

$\dagger$ These authors contributed equally to this work.

\section{Notes}

The authors declare no competing financial interests.

\section{ACKNOWLEDGMENT}

B.M. and L.C., acknowledge King Abdullah University of Science and Technology (KAUST) for support and the KAUST Supercomputing Laboratory for providing computational resources of the supercomputer Shaheen II.

\section{REFERENCES}

(1) (a) Sundberg, R. J. Indoles, Academic Press, San Diego, 1996 (b) Somei, M.; Yamada, F. Nat. Prod. Rep. 2005, 22, 73. (c) Kochanowska-Karamyan, A. J.; Hamann, M. T. Chem. Rev. 2010, $110,4489$.

(2) For recent reviews on the synthesis and functionalization of indoles, see: (a) Cacchi, S.; Fabrizi, G. Chem. Rev. 2005, 105, 2873. (b) Ackermann, L. Synlett 2007, 507. (c) Krüger, K.; Tillack, A.; Beller, M. Adv. Synth. Catal. 2008, 350, 2153. (d) Bandini, M.; Eichholzer, A. Angew. Chem. Int. Ed. 2009, 48, 9608. (e) Taber, D. F.; Tirunahari, P. K. Tetrahedron 2011, 67, 7195. (f) Shiri, M. Chem. Rev. 2012, 112, 3508. (g) Bandini, M. Org. Biomol. Chem. 2013, 11 , 5206.

(3) For a recent review on transition metal catalyzed C-H activation of indoles, see: Sandtorv, A. H. Adv. Synth. Catal. 2015, 357, 2403.

(4) For recent reviews on Mn-catalyzed C-H activation reactions, see: (a) Wang, C. Synlett 2013, 24, 1606. (b) Liu, W.; Ackermann, L. ACS Catal. 2016, 6, 3743. (c) Valyaev, D. A.; Lavigne, G.; Lugan, N. Coord. Chem. Rev. 2016, 308, 191.

(5) For representative examples of Mn-catalyzed C-H activation, see: (a) Kuninobu, Y.; Nishina, Y.; Takeuchi, T.; Takai, K. Angew. Chem. Int. Ed. 2007, 46, 6518. (b) Zhou, B.; Chen, H.; Wang, C. J. Am. Chem. Soc. 2013, 135, 1264. (c) He, R.; Huang, Z.-T.; Zheng, Q.Y.; Wang, C. Angew. Chem. Int. Ed. 2014, 53, 4950. (d) Zhou, B.; Ma, P.; Chen, H.; Wang, C. Chem. Commun. 2014, 50, 14558. (e) Liu, W.; Zell, D.; John, M.; Ackermann, L. Angew. Chem. Int. Ed. 2015, 54, 4092. (f) Zhou, B.; Hu, Y.; Wang, C. Angew. Chem. Int. Ed. 2015, 54, 13659. (g) Liu, W.; Bang, J.; Zhang, Y.; Ackermann, L. Angew. Chem. Int. Ed. 2015, 54, 14137. (h) Shi, L.; Zhong, X.; She, H.; Lei, Z.; Li, F. Chem. Commun. 2015, 51, 7136. (i) Sueki, S.; Wang, Z.; Kuninobu, Y. Org. Lett. 2016, 18, 304. (j) Liu, W.; Richter, S. C.; Zhang, Y.; Ackermann, L. Angew. Chem. Int. Ed. 2016, 55, 7747. (k) Conde, A.; Sabenya, G.; Rodríguez, M.; Postils, V.; Luis, J. M.; Díaz-Requejo, M. M.; Costas, M.; Pérez, P. J. Angew. Chem. Int. Ed. 2016, 55, 6530. (1) Castro, S.; Fernández, J. J.; Fañanás, F. J.; Vicente, R.; Rodríguez, F. Chem. Eur. J. 2016, 22, 9068. (m) Yang, X.; Jin, X.; Wang, C. Adv. Synth. Catal. 2016, 358, 2436. (n) Liang, Y.-F.; Massignan, L.;
Liu, W.; Ackermann, L. Chem. Eur. J. 2016, 22, 14856. (o) Sueki, S.; Wang, Z.; Kuninobu, Y. Org. Lett. 2016, 18, 304. (p) Yahaya, N. P.; Appleby, K. M.; Teh, M.; Wagner, C.; Troschke, E.; Bray, J. T. W.; Duckett, S. B.; Hammarback, L. A.; Ward, J. S.; Milani, J.; Pridmore, N. E.; Whitwood, A. C.; Lynam, J. M.; Fairlamb, I. J. S. Angew. Chem. Int. Ed., 2016, 55, 12455. (q) Lv, X.-L.; Wang, K.; Wang, B.; Su, J.; Zou, X.; Xie, Y.; Li, J.-R.; Zhou, H.-C. J. Am. Chem. Soc. 2017, 139, 211. (r) Lu, Q.; Klauck, F. J. R.; Glorius, F. Chem. Sci. 2017, 8, 3379. (s) Lu, Q.; Greßies, S.; Klauck, F. J. R.; Glorius, F. Angew. Chem. Int. Ed. 2017, 56, 6660. (t) Wang, C.; Wang, A.; Rueping, M. Angew. Chem. Int. Ed. 2017, 56, 9935. (u) Lu, Q.; Greßies, S.; Cembellín, S.; Klauck, F. J. R.; Daniliuc, C. G.; Glorius, F. Angew. Chem. Int. Ed. 2017, 56, 12778. (v) Zhu, C.; Schwarz, J. L.; Cembellín, S.; Greßies, S.; Glorius, F. Angew. Chem. Int. Ed. 2018, 57, 437. (w) Lu, Q.; Cembellín Santos, S.; Greßies, S.; Singha, S.; Daniliuc, C.; Glorius, F. Angew. Chem. Int. Ed. 2018, 57, 1399. (x) Wang, H.; Pesciaioli, F.; Oliveira, J. C. A.; Warratz, S.; Ackermann, L. Angew. Chem. Int. Ed. 2017, 56, 15063.

(6) (a) Liang, Y.-F.; Müller, V.; Liu, W.; Münch, A.; Stalke, D.; Ackermann, L. Angew. Chem. Int. Ed. 2017, 56, 9415. (b) Zell, D.; Dhawa, U.; Müller, V.; Bursch, M.; Grimme, S.; Ackermann, L. ACS Catal. 2017, 7, 4209. (c) Wang, H.; Lorion, M. M.; Ackermann, L. Angew. Chem. Int. Ed. 2017, 56, 6339. (d) Meyer, T. H.; Liu, W.; Feldt, M.; Wuttke, A.; Mata, R. A.; Ackermann, L. Chem. Eur. J. 2017, 23, 5443. (e) Ruan, Z.; Sauermann, N.; Manoni, E.; Ackermann, L. Angew. Chem. Int. Ed. 2017, 56, 3172. (f) Zhou, B.; Hu, Y.; Liu, T.; Wang, C. Nat. Commun. 2017, 8, 1169.

(7) For examples of metal catalyzed $\mathrm{C} 2$-selective $\mathrm{C}-\mathrm{H}$ alkylation of indoles with diazo compounds, see: (a) Chan, W.-W.; Yeung, S.-H.; Zhou, Z.; Chan, A.S.C.; Yu, W.-Y. Org. Lett. 2010, 12, 604. (b) Shi, J.; Yan, Y.; Li, Q.; Xu, H. E.; Yi, W. Chem. Commun. 2014, 50, 6483. (c) Liu, X.-G.; Zhang, S.-S.; Wu, J.-Q.; Li, Q.; Wang, H. Tetrahedron Lett. 2015, 56, 4093. (d) Wang, L.; Li, Z.; Qu, X.; Peng, W.-M.; Hu, S.-Q.; Wang, H.-B. Tetrahedron Lett. 2015, 56, 6214. (e) Wu, J.-Q.; Yang, Z.; Zhang, S.-S.; Jiang, C.-Y.; Li, Q.; Huang, Z.-S.; Wang, H. ACS Catal. 2015, 5, 6453. (f) Zhao, D.; Kim, J. H.; Stegemann, L.; Strassert, C. A.; Glorius, F. Angew. Chem. Int. Ed. 2015, 54, 4508. (g) Wan, K.; Li, Z.; Qu, X.; Wang, F.; Wang, L. Catalysts 2016, 6, 89.

(8) For selected reviews on metal catalyzed carbene migratory insertion, see: (a) Davies, H. M. L.; Beckwith, R. E. Chem. Rev. 2003, 103, 2861. (b) Doyle, M. P.; Duffy, R.; Ratnikov, M.; Zhou, L. Chem. Rev. 2010, 110, 704. (c) Davies, H. M. L.; Morton, D. Chem. Soc. Rev. 2011, 40, 1857. (d) Zhao, X.; Zhang, Y.; Wang, J. Chem. Commun. 2012, 48, 10162. (e) Shao, Z.-H.; Zhang, H.-B. Chem. Soc. Rev. 2012, 41, 560. (f) Xia, Y.; Zhang, Y.; Wang, J.-B. ACS Catal. 2013, 3, 2586. (g) Xia, Y.; Qiu, D.; Wang, J. Chem. Rev. 2017, 117, 13810.

(9) Please see SI for more information.

(10) An explicit model employing coordination of THF molecule by replacement of one carbonyl ligand from $\mathbf{C}_{\mathbf{3}}$ was also included in our study. Unfortunately, the $\mathrm{C}-\mathrm{H}$ activation transition state, [1-2thf $]^{\ddagger}$ is very high in energy $\left(\Delta G^{\ddagger}=41.2 \mathrm{kcal} / \mathrm{mol}\right)$, even higher than $[1-2-I]^{*}$ by $5.1 \mathrm{kcal} / \mathrm{mol}$ (see Figure $\mathrm{S} 1$ in the SI). 
Insert Table of Contents artwork here

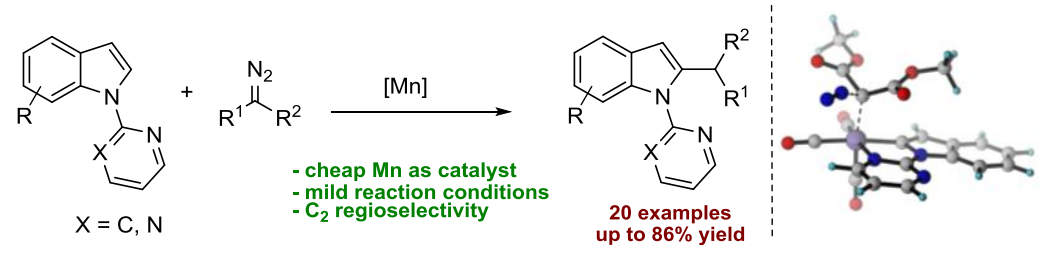

5 